\title{
Dependence of cloud properties derived from spectrally resolved visible satellite observations on surface temperature
}

\author{
T. Wagner ${ }^{1,2}$, S. Beirle ${ }^{1}$, T. Deutschmann ${ }^{2,1}$, M. Grzegorski ${ }^{2,1}$, and U. Platt ${ }^{2}$ \\ ${ }^{1}$ MPI for Chemistry, Mainz, Germany \\ ${ }^{2}$ Institut für Umweltphysik, University of Heidelberg, Heidelberg, Germany
}

Received: 13 November 2007 - Published in Atmos. Chem. Phys. Discuss.: 23 November 2007

Revised: 4 March 2008 - Accepted: 21 April 2008 - Published: 5 May 2008

\begin{abstract}
Cloud climate feedback constitutes the most important uncertainty in climate modelling, and currently even its sign is still unknown. In the recently published report of the intergovernmental panel on climate change (IPCC), 6 out of 20 climate models showed a positive and 14 a negative cloud radiative feedback in a doubled $\mathrm{CO}_{2}$ scenario. The radiative budget of clouds has also been investigated by experimental methods, especially by studying the relation of satellite observed broad band shortwave and longwave radiation to sea surface temperature. Here we present a new method for the investigation of the dependence of cloud properties on temperature changes, derived from spectrally resolved satellite observations in the visible spectral range. Our study differs from previous investigations in three important ways: first, we directly extract cloud properties (effective cloud fraction and effective cloud top height) and relate them to surface temperature. Second, we retrieve the cloud altitude from the atmospheric $\mathrm{O}_{2}$ absorption instead from thermal IR radiation. Third, our correlation analysis is performed using 7.5 years of global monthly anomalies (with respect to the average of the same month for all years). For most parts of the globe (except the tropics) we find a negative correlation of effective cloud fraction versus surface-near temperature. In contrast, for the effective cloud top height a positive correlation is found for almost the whole globe. Both findings might serve as an indicator for an overall positive cloud radiative feedback. Another peculiarity of our study is that the cloud-temperature relationships are determined for fixed locations (instead to spatial variations over selected areas) and are based on the "natural" variability over several years (instead the anomaly for a strong El-Nino event). From a detailed comparison to cloud properties from the In-
\end{abstract}

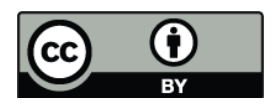

Correspondence to: $\mathrm{T}$. Wagner (thomas.wagner@mpch-mainz.mpg.de) ternational Satellite Cloud Climatology Project (ISCCP), in general good agreement is found. However, also systematic differences occurred indicating that our results provide independent and complementary information on cloud properties. Climate models should thus aim to reproduce our findings. Recommendations for the development of a "processor" to convert model results into the cloud sensitive quantities observed by the satellite are given.

\section{Introduction}

Clouds have a strong impact on both, the short-wave solar radiation and on the outgoing thermal radiation (e.g. Ramanathan and Inamdar, 2006). If cloud cover increases, less solar radiation reaches the ground, but also more thermal radiation from the surface will be trapped in the atmosphere. Both effects influence the surface-near temperature (ST) with opposite signs, and their net effect depends on various cloud properties, especially on the cloud altitude (Stephens, 2005; Cess et al., 1992; Hartmann et al., 2001; Fu et al., 2002; Cess and Udelhofen, 2003; Webb et al., 2006; Kubar et al., 2007). Today, the magnitude, and even the sign of cloud feedback is still not known (see e.g. the IPCC 4th assessment report: Solomon et al., 2007, and references therein).

Besides modelling studies (Cess et al., 1990, 1996; Soden and Held, 2006; Webb et al., 2006; Larson and Hartmann, 2003; Bony and Dufresne, 2005; Williams et al., 2006), climate feedbacks have been investigated also from experimental data and their combination with model results. Most studies investigated the relation of broad band short wave and long wave radiation and cloud properties to spatial variations of the surface temperature (Ramanathan et al., 1989; Harrison et al., 1990; Stephens and Greenwald, 1991). Other studies investigated seasonal variations, anomalies during strong

Published by Copernicus Publications on behalf of the European Geosciences Union. 
El-Nino events or temporal trends (Cess et al., 1992, 2003; Bony et al., 1997a, b; Tian and Ramanathan, 2002). Most of these studies were restricted to specific areas, e.g. the continents or the tropics.

In this study we investigate the cloud relationships for fixed locations on a global scale using correlation analyses of monthly anomalies of effective cloud fraction and effective cloud top height (derived from the atmospheric $\mathrm{O}_{2}$ absorption) with those of ST. It should be noted that in contrast to trend analyses, our correlation studies are much less affected by instrumental degradation. The effective cloud fraction and effective cloud top height information is derived from 7.5 years of observations of the Global Ozone Monitoring Experiment (GOME) on board the European research satellite ERS-2. We relate the GOME results to ST observations for the same period (ST data are obtained from the Goddard Institute for Space Studies (Hansen et al., 2001; Reynolds et al., 2002), GISS, see Sect. 2.6).

\section{Data sets used in this study}

\subsection{The GOME instrument}

The GOME instrument aboard the European research satellite ERS-2 measures sunlight reflected from the Earth's atmosphere and surface covering the wavelength range between 240 and $790 \mathrm{~nm}$ with moderate spectral resolution (Burrows et al., 1999) (0.2-0.4 nm FWHM). The satellite operates in a nearly polar, sun-synchronous orbit at $780 \mathrm{~km}$ altitude with an equator crossing time of approximately 10:30 a.m. local time. This has to be taken into consideration for the interpretation of our results, which might be only representative for mid-morning because of the diurnal variation of clouds (Bergman and Salby, 1996). The ground pixels cover an area of $320 \mathrm{~km}$ east to west by $40 \mathrm{~km}$ north to south. Simultaneous to the spectral channels, also broad band intensities are measured by the so called polarization monitoring devices (PMD). Compared to the spectral channels, they have a much finer spatial resolution of $20 \times 40 \mathrm{~km}^{2}$. The Earth's surface is entirely covered within 3 days, and poleward from about $70^{\circ}$ latitude within 1 day.

\subsection{Effective cloud fraction derived from GOME}

An effective cloud fraction (CF) is derived using the Heidelberg Iterative Cloud Retrieval Utilities (HICRU, Grzegorski et al., 2006), which is based on the PMD observations. The $\mathrm{CF}$ is a product of the cloud top reflectance (depending on the cloud optical depth) and the geometrical cloud fraction; it is almost independent from cloud height. Effective cloud fractions range from 0 to 1 with individual values occasionally also slightly above and below this range due to the applied threshold method (Grzegorski et al., 2006). From sensitivity studies we estimate the absolute uncertainty of an individual measurement over surfaces free of snow and ice to range from $2 \%$ for almost clear pixels to $5 \%$ for $\mathrm{CF}>20 \%$ (expressed in absolute CF). The uncertainties for small CF are also confirmed by the scatter of the lowest CF around zero. Note that snow and ice-covered surfaces are classified as cloudy, leading to artificially high CF, especially in polar regions.

\section{$2.3 \mathrm{O}_{2}$ absorption derived from GOME}

The $\mathrm{O}_{2}$ absorption at $630 \mathrm{~nm}$ is analysed using differential optical absorption spectroscopy (DOAS, see Platt, 1994). Besides the $\mathrm{O}_{2}$ absorption also spectra for the absorptions of $\mathrm{H}_{2} \mathrm{O}$ and the oxygen dimer $\mathrm{O}_{4}$, as well as a Ring spectrum are included in the analysis; details of the retrieval can be found in Wagner et al. (2006a). One specific advantage of the DOAS method is that it analyses differential absorption structures and is therefore hardly affected by instrumental degradation. The statistical uncertainty of the retrieved $\mathrm{O}_{2}$ absorption as determined from the non-linear least squares fitting routine is negligible $(<0.3 \%)$ for monthly mean values. The observed $\mathrm{O}_{2}$ absorption depends on $\mathrm{CF}$ and the effective cloud top height (CTH) of the cloudy part of the observed scene.

The retrieved quantity of the DOAS analysis is the differential optical depth (DOD) of the $\mathrm{O}_{2}$ absorption at $630 \mathrm{~nm}$ (for the spectral resolution of the GOME instrument). With the knowledge of the $\mathrm{O}_{2}$ absorption cross section, the measured $\mathrm{O}_{2}$ DOD can be converted into the $\mathrm{O}_{2}$ slant column density (the $\mathrm{O}_{2}$ concentration integrated along the atmospheric absorption path). In order to avoid any dependence on the exact value of the $\mathrm{O}_{2}$ absorption cross section, in this study we decided to apply a normalisation approach to the retrieved $\mathrm{O}_{2}$ DOD (for details see Sect. 2.4).

2.4 Retrieval of the effective cloud top height using radiative transfer modeling

The calculation of the effective cloud top height $(\mathrm{CTH})$ from the observed effective cloud fraction (CF) and $\mathrm{O}_{2}$ absorption is based on the results of atmospheric radiative transfer modelling of the $\mathrm{O}_{2}$ absorption. While the results of such simulations provide the best means for the interpretation of the $\mathrm{O}_{2}$ absorption measurements, it is also instructive to discuss the general dependencies of the observed $\mathrm{O}_{2}$ absorption on cloud properties:

1. First, the observed $\mathrm{O}_{2}$ absorption depends on the CTH: with increasing $\mathrm{CTH}$ an increasing fraction of the atmospheric $\mathrm{O}_{2}$ absorption is shielded. Thus high clouds strongly reduce the observed $\mathrm{O}_{2}$ absorption (shielding effect).

2. Second, the observed $\mathrm{O}_{2}$ absorption depends on the cloud top reflectance: with increasing brightness of the cloud top (depending mainly on the cloud optical depth) 
an increasing number of the measured photons originates from atmospheric layers at the cloud top (having "seen" a larger $\mathrm{O}_{2}$ absorption than photons scattered at higher altitudes). In addition, multiple scattering inside the clouds (also depending on the cloud optical depth) can further increase the atmospheric absorption paths. Both effects increase the observed $\mathrm{O}_{2}$ absorption (the strongest increase is found for large cloud optical depth) and we will refer to them as albedo effect. For low cloud altitudes, the albedo effect can even overcompensate the shielding effect.

3. Third, the measured $\mathrm{O}_{2}$ absorption depends on the $\mathrm{CF}$. The higher the $\mathrm{CF}$ is, the higher is the deviation of the measured $\mathrm{O}_{2}$ absorption from the value for the cloud free case.

We investigated the dependence of the measured $\mathrm{O}_{2}$ absorption on $\mathrm{CF}$ and $\mathrm{CTH}$ in a quantitative way using our full spherical Monte-Carlo radiative transfer model TRACY-2 (Deutschmann and Wagner, 2006; Wagner et al., 2007). For the modeling of the $\mathrm{O}_{2}$ absorption of an individual satellite ground pixel, we use the independent pixel approximation: the $\mathrm{O}_{2}$ absorption of the total ground pixel is the average of the modeled $\mathrm{O}_{2}$ absorptions for the clear and for the cloudy parts (weighted by their geometrical fraction and their respective top of atmosphere reflectance). For the clear part, only Rayleigh scattering and surface reflection is considered. For the cloudy part, in addition to these effects, also scattering by the cloud particles is taken into account. Note that in the current version of the algorithm, the Earth's topography is not taken into account and the surface elevation is set to zero. Thus several areas had to be excluded from our correlation studies, see below. For the cloudy part, we assumed the following standardised cloud properties: optical depth: 50, phase function: Henyey-Greenstein using an asymmetry parameter of 0.85 ; single scattering albedo: 1 , vertical thickness: $1 \mathrm{~km}$. Note that the albedo of these clouds is about $80 \%$, similar to the cloud albedo implicitly assumed in the HICRU algorithm (Grezegorski et al., 2006). It should also be noted that the CF determined by HICRU is representative for the spectral range of the green and red PMD. From sensitivity tests it was found that the CF determined independently in both PMD channels are almost identical. Therefore we conclude that the HICRU CF are well suited for the scaling of the $\mathrm{O}_{2}$ absorptions of the clear and cloudy part. The radiative transfer simulations were performed for three different values of the surface albedo $(2 \%, 10 \%, 30 \%)$. The modeled normalized $\mathrm{O}_{2}$ absorptions as a function of $\mathrm{CF}$ and CTH are shown in Fig. 1. The calculated relationships - in particular for low $\mathrm{CF}$ - are strongly dependent on the surface albedo. In contrast, the dependence on the assumed value of the asymmetry parameter (not shown) is very weak, because for the assumed OD of 50 the number of scattering events is large.

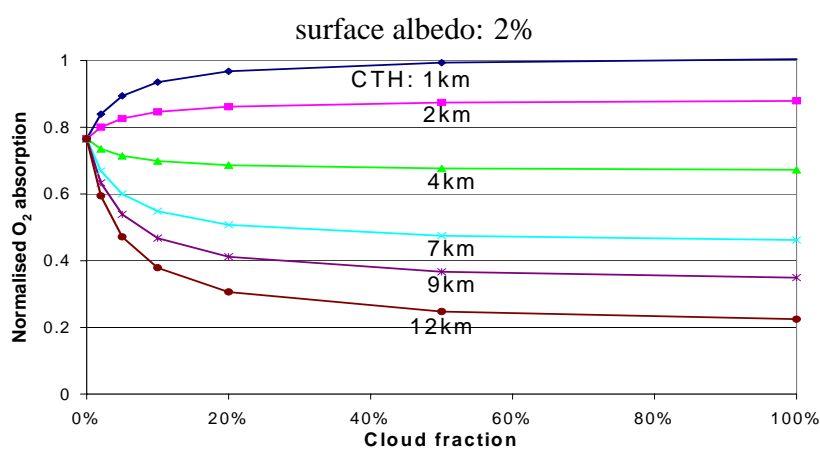

surface albedo: $10 \%$

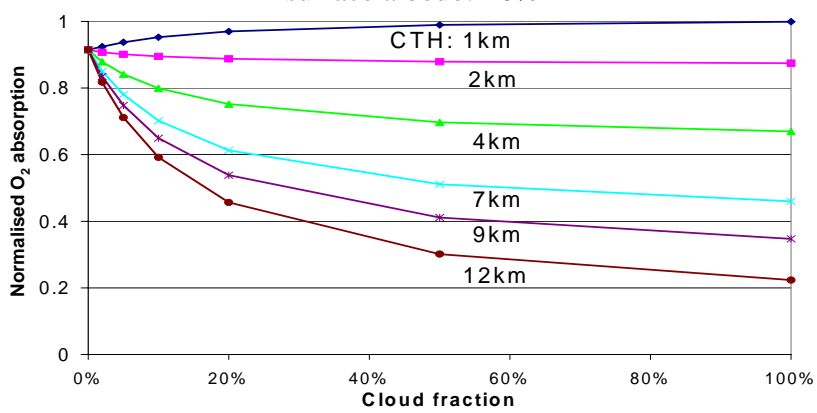

surface albedo: $30 \%$

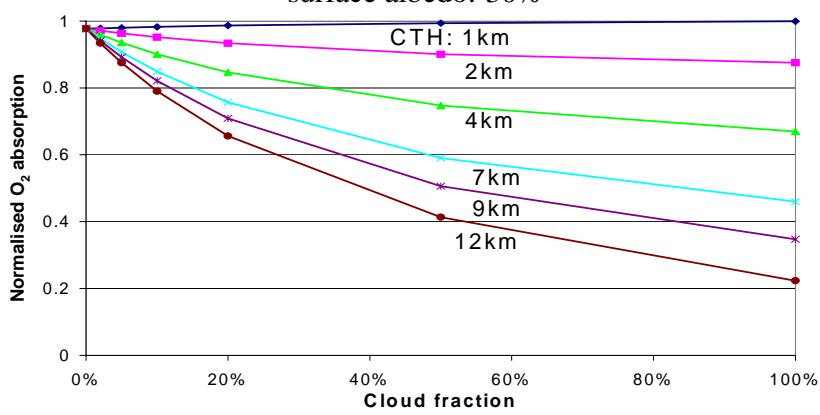

Fig. 1. Simulation of the measured normalised $\mathrm{O}_{2}$ absorption as a function of $\mathrm{CF}$ and $\mathrm{CTH}$ calculated from radiative transfer modeling. The results are for different values of the surface albedo (top: $2 \%$, center: $10 \%$, bottom: $30 \%$ ). Depending on the CTH and the surface albedo, clouds can increase or decrease the measured $\mathrm{O}_{2}$ absorption compared to clear sky conditions. The results are obtained for a line of sight angle of $-90^{\circ}$ (nadir) and a solar zenith angle of $20^{\circ}$.

Finally, the $\mathrm{O}_{2}$ absorptions are normalised with respect to the maximum $\mathrm{O}_{2}$ absorptions found for the same viewing geometry (the same solar zenith angle, line of sight angle and relative azimuth angle). The determination of the maximum $\mathrm{O}_{2}$ absorption was performed for each individual month using all measurements over the oceans of the respective month for the years between 1996-2003. Note that for each month 6 sets of maximum $\mathrm{O}_{2}$ absorptions as a function of the solar zenith angle are determined, three for the three line of sight angles and two sets for the two hemispheres. This procedure was chosen, because the combinations of line of sight angles 


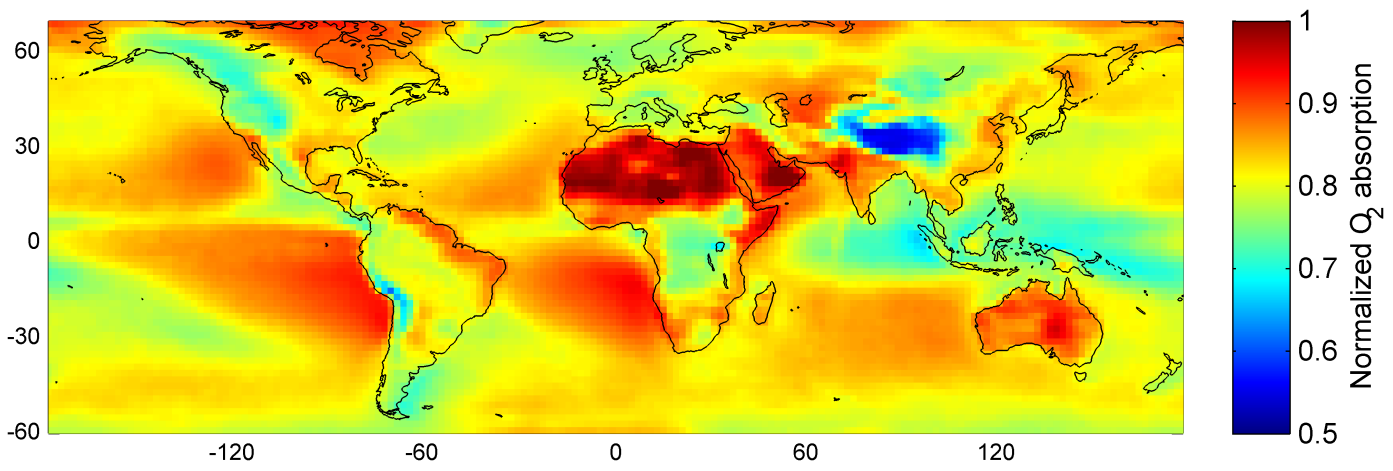

Fig. 2. Normalised $\mathrm{O}_{2}$ absorption (with respect to the maximum $\mathrm{O}_{2}$ absorption, see Sect. 2.4) averaged for the period January 1996December 2002.

and relative azimuth angles differ for both hemispheres and vary also with season. The maximum $\mathrm{O}_{2}$ absorptions are determined with an automated routine on bins of $1^{\circ}$ solar zenith angle. The results were visually inspected to avoid the possible effect of outliers.

The normalization procedure using the maximum $\mathrm{O}_{2}$ absorptions has the advantage that the calculation of the $\mathrm{CTH}$ can be performed using a single inversion scheme for a wide range of solar zenith angles $\left(\mathrm{SZA}<85^{\circ}\right)$. In the normalization procedure we also applied a correction for the effect of non-linearity between the measured $\mathrm{O}_{2}$ absorption (for the resolution of the instrument) and the corresponding integrated $\mathrm{O}_{2}$ concentration along the atmospheric absorption path (Wagner et al., 2003, 2005). The global averaged normalised $\mathrm{O}_{2}$ absorption is shown in Fig. 2. The observed patterns mainly represent the shielding effect of clouds: small $\mathrm{O}_{2}$ absorptions are found in regions with high cloud top heights (a similar effect is found for regions with high surface elevation). Also the influence of the cloud frequency can be seen, e.g. with the highest values over the Sahara.

Based on the modeled dependence of the normalized $\mathrm{O}_{2}$ absorption we calculated the global distribution of the mean $\mathrm{CTH}$ from the average values of the $\mathrm{CF}$ and the $\mathrm{O}_{2}$ absorption (Fig. 2) for the period January 1996-July 2003. For these calculations we also made use of the surface albedo at $670 \mathrm{~nm}$ as derived by Koelemeijer et al. (2003) (see Fig. 3). For each $2 \times 2$ degree grid of the globe the CTH was determined by linear interpolation of the modeled dependencies (Fig. 1) to the respective measured values of the $\mathrm{CF}, \mathrm{CTH}$ and surface albedo.

Note that in our current algorithm, we had to exclude continental areas with low $\mathrm{CF}(<7 \%)$ and high surface elevation $\left(>1.2 \mathrm{~km}\right.$ on a $2^{\circ} \times 2^{\circ}$ grid). For such conditions, the measured $\mathrm{O}_{2}$ absorption is reduced, because the total atmospheric column is smaller than for zero elevation. In our current algorithm, this decreased $\mathrm{O}_{2}$ absorption would be apparently interpreted as shielding effect due to clouds. In connection with the strong dependence of the $\mathrm{O}_{2}$ absorption on $\mathrm{CF}$ (see Fig. 1) this would lead to unrealistically high CTH. Note that, for areas with surface elevation $<1.2 \mathrm{~km}$, still small errors in the CTH determination remain, especially for small CF. Nevertheless, in this study, we are primarily interested in the correlation of the monthly anomalies, which are hardly affected by these systematic errors. In future versions of our algorithm, however, this limitation can be generally corrected considering information on the global surface elevation in the radiative transfer modeling.

\subsection{Comparison to ISCCP data}

We compared the GOME results of CF and CTH with satellite derived cloud properties from the International Satellite Cloud Climatology Project (ISCCP, D2 product, see e.g. Schiffer and Rossow (1983), Rossow and Schiffer (1999), and http://isccp.giss.nasa.gov/climanal.html). It should be noted that from such a comparison no exact agreement can be expected because of the different sampling times, spectral ranges, spatial resolutions and methodologies used. In particular, the information on CTH is derived using completely different approaches (for ISCCP, CTH is derived from thermal IR observations).

First, we compare annual and seasonal averages of the GOME CF with ISCCP cloud amounts. Since ISCCP cloud amounts include clouds with different optical thickness (and thus different reflectance), they can not directly be compared to the GOME CF, which implicitly assumes a cloud albedo of about $80 \%$. To allow a meaningful comparison, we constructed a correction function for the ISCCP cloud amounts which takes into account the effects of varying cloud optical depth (see also Koelemeijer et al., 2002). For this correction function we used our radiative transfer model and assumed clouds with a geometrical thickness of $1 \mathrm{~km}$, a single scattering albedo of 1 and a Henyey Greenstein function with an asymmetry parameter of 0.8 (note that the vertical structure of the assumed clouds has only negligible influence on the correction function). Using this correction function, $\mathrm{CF}$ from ISCCP are calculated from the global distribution of ISCCP cloud amount and cloud optical depth and compared 


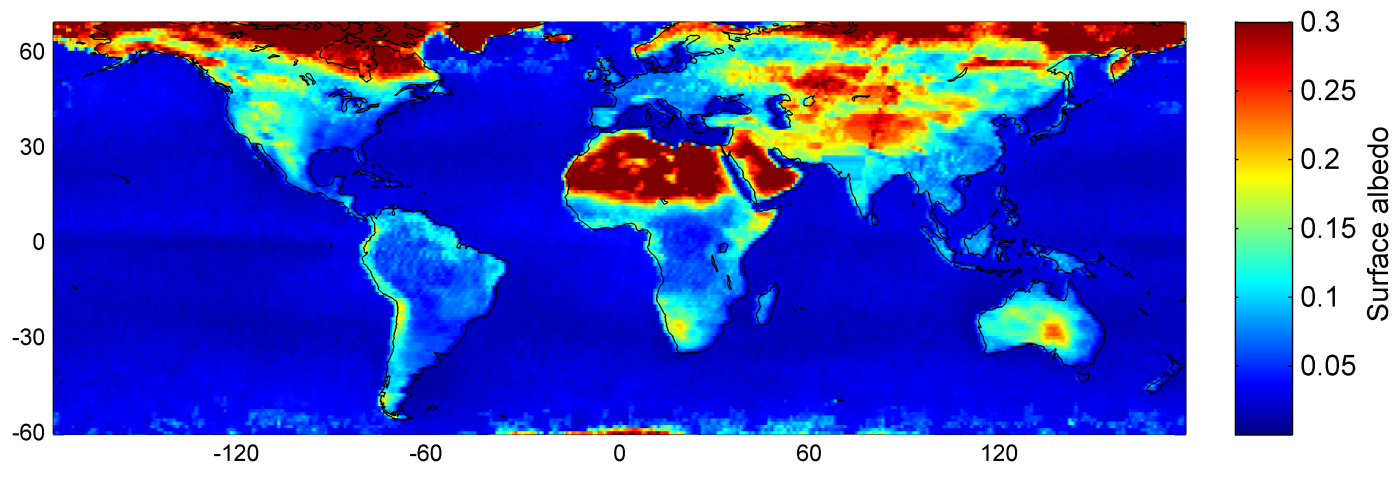

Fig. 3. Annual average surface albedo $(670 \mathrm{~nm})$ taken from Koelemeijer et al. (2003).

to GOME CF (Fig. 4). In general, good agreement of the spatial patterns in both data sets is found. For the absolute values the differences can be substantial for several regions, as should be expected because of the rough assumptions made in the correction function. Over polar regions, GOME CF show artificially high values caused by snow and ice. The importance of the correction function for the ISCCP data is also illustrated in Fig. 5, which shows the spatial correlation of the annual averages for ISCCP cloud amounts and the corrected ISCCP CF with GOME CF. Note that the slope of the regression line depends mainly on the asymmetry parameter assumed in the correction scheme.

In a second step, we also compared the GOME CTH to ISCCP cloud pressures. First, we converted the ISCCP cloud pressures into cloud top heights using the pressure profile of the US standard atmosphere (United States Committee on Extension to the Standard Atmosphere, 1976). Then, as for the $\mathrm{CF}$, we developed a correction scheme for the conversion of ISCCP cloud top height into effective cloud top height. The respective correction function depends on the optical thickness, but also on the cloud top height itself and on the surface albedo (note that for the seasonal averages, the respective averages of the surface albedo were used). The annual and seasonal averages of the extracted ISCCP CTH together with the GOME CTH are presented in Fig. 6. Again, in general good agreement of the spatial patterns is found. For the absolute values the differences can be substantial for several regions, as should be expected because of the rough assumptions made in the correction function. The importance of the correction function for the comparison to ISCCP data is illustrated in Fig. 7, which shows the spatial correlation of the annual averages for uncorrected ISCCP CTH and the corrected ISCCP CTH with GOME CTH.

As one outcome of the comparison of cloud products from GOME and ISCCP, we conclude that especially the GOME CTH derived from the $\mathrm{O}_{2}$ absorption provides complementary information to ISCCP cloud pressures. Using GOME CTH data in addition to ISCCP cloud products for model comparisons should yield additional information on the cloud vertical structure. For that purpose, the use of a
"GOME-simulator" could be useful, which directly generates the cloud sensitive quantities $\left(\mathrm{O}_{2}\right.$ absorption and $\left.\mathrm{CF}\right)$ observed by GOME from the model results. The development of such a GOME simulator is described in Sect. 3.3.

\subsection{Surface temperature data}

We relate the GOME results to surface near temperatures (ST) observations for the same period, which were taken from the Goddard Institute for Space Studies (GISS, see http: //www.giss.nasa.gov/data/update/gistemp/). Over the continents, the ST data set is determined from meteorological observations. Over the oceans, the sea surface temperature is provided, which is constructed from in-situ observations (from ships and buoys), satellite observations of temperatures (day-time and night-time IR measurements), and ice coverage (microwave measurements over polar regions). The spatial variability of the sea surface temperatures is mainly derived from the satellite observations, where the night-time IR observations have the highest weight. The in-situ observations are used to correct biases in the satellite data (e.g. after strong volcanic eruptions). For our analysis we used monthly mean values of ST. More details on the ST data set can be found in Hansen et al. (2001) and Reynolds et al. (2002).

\section{Results}

In this chapter we present correlation analyses of the cloud properties derived from GOME observations with ST. They are performed as follows: from the individual observations of the $\mathrm{CF}$ and $\mathrm{O}_{2}$ absorption (and also ST) we calculated monthly average values for the period January 1996 to July 2003. From these monthly averages, anomalies for individual months are derived (deviation from the mean value of the respective month for all years). Using these monthly anomalies we performed correlation analyses of the CF versus ST and the $\mathrm{O}_{2}$ absorption versus ST. The technique of correlations of monthly anomalies allows to extract valuable information on cloud-ST relationships from rather short periods of time. Note that the amplitude of the ST anomalies for the 
ISCCP corrected
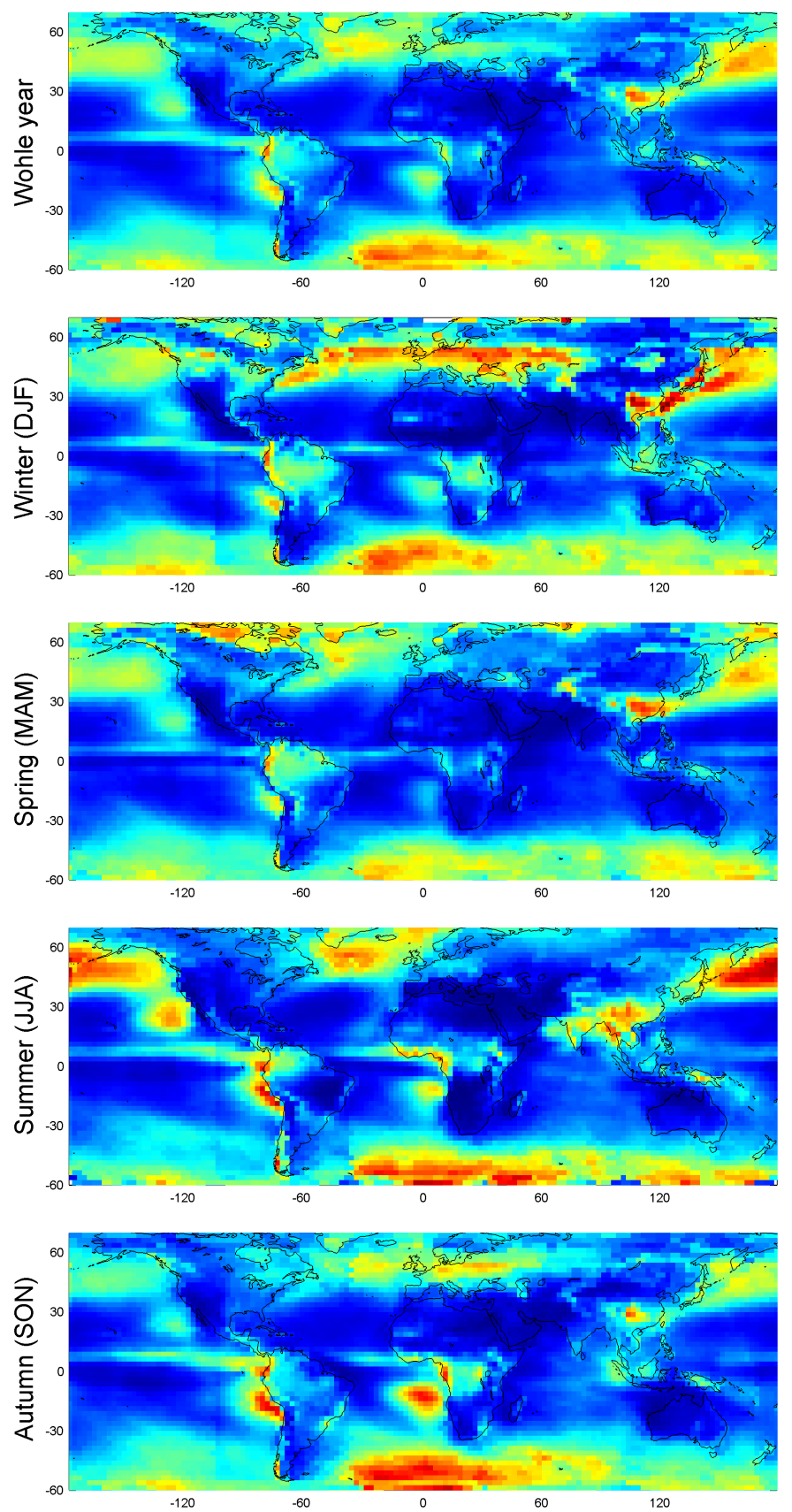

GOME
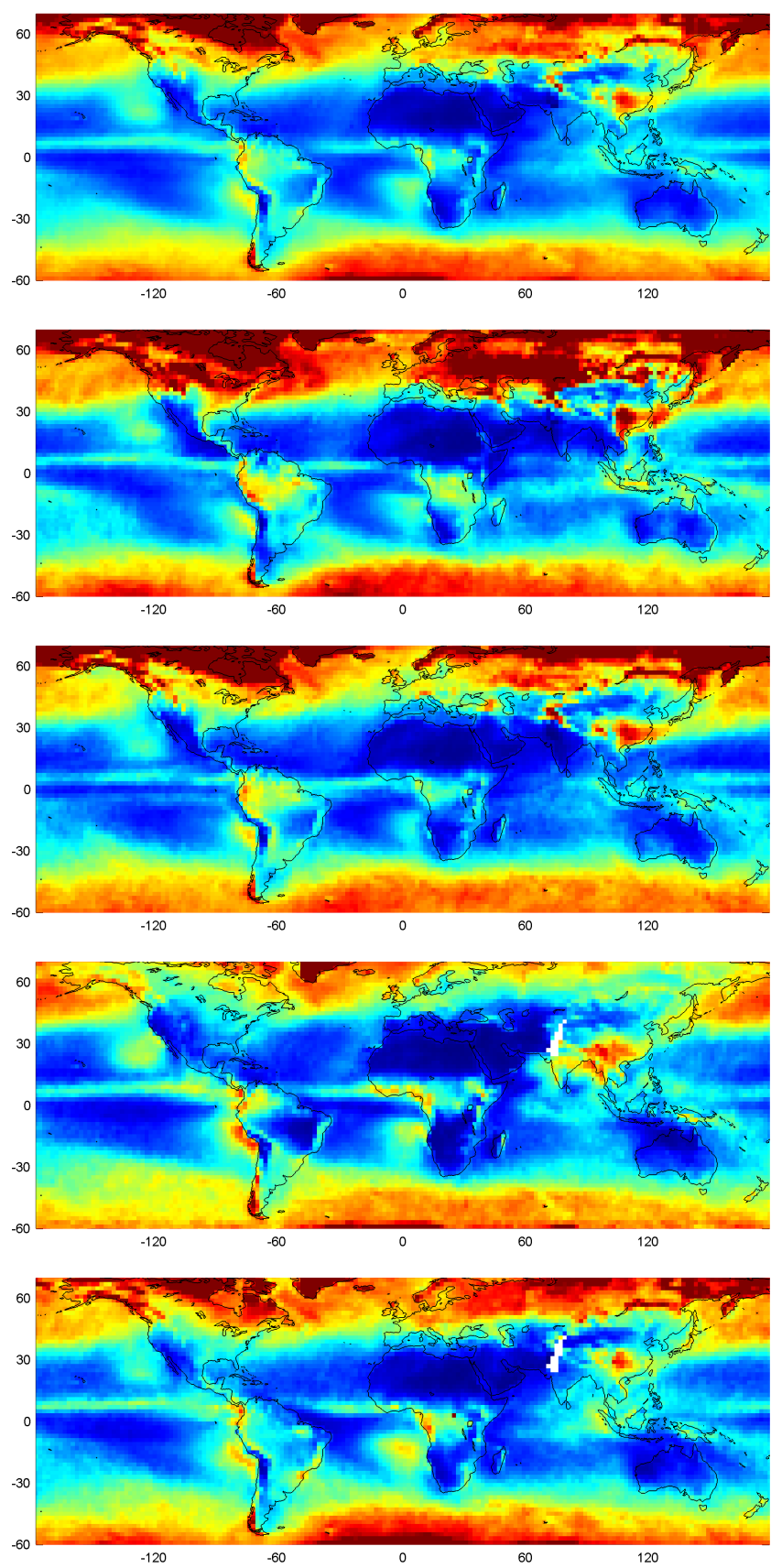

$-60$

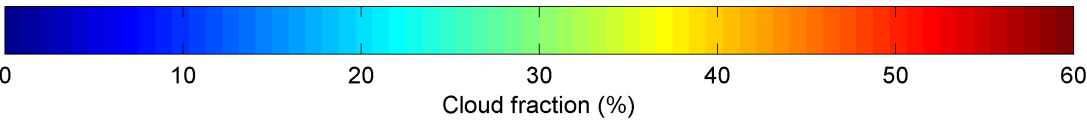

Fig. 4. Comparison of the effective cloud fraction from GOME and ISCCP (annual and seasonal averages) for the period 1996-2003. For the ISCCP data a correction procedure was developed which converts cloud amount and cloud optical depth into effective cloud fraction (see also text). Note that in polar regions the GOME data are strongly affected by snow and ice, which are mis-interpreted as clouds.

selected period ranges between about $2 \mathrm{~K}$ and $15 \mathrm{~K}$, depending on location on earth, with the highest amplitudes over the continents (see Fig. 8). Global maps of the calculated corre- lation coefficients of the $\mathrm{CF}$ and the $\mathrm{O}_{2}$ absorption versus ST are shown in Fig. 9. Over large parts of the globe negative correlations are found for both quantities indicating that a 

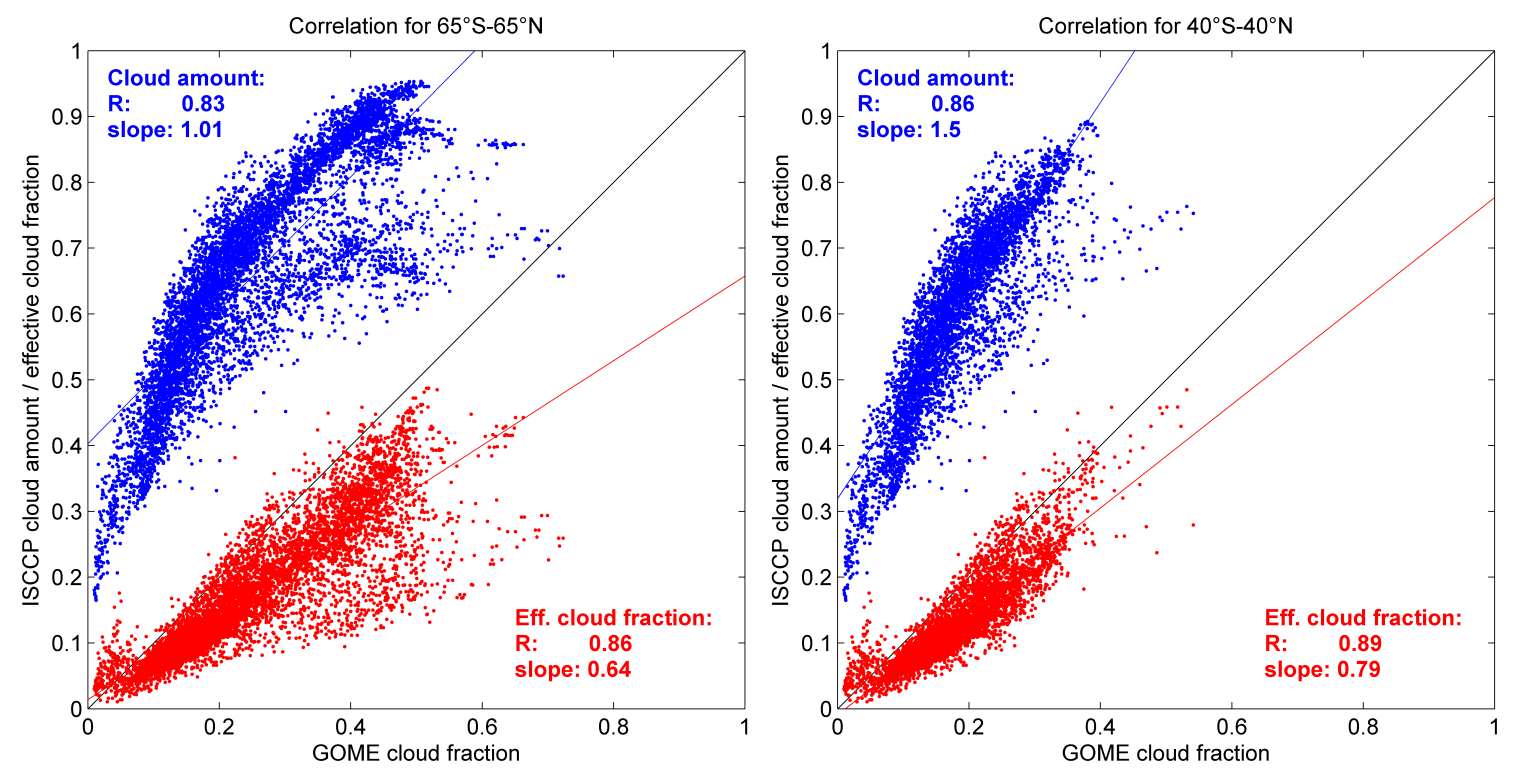

Fig. 5. Spatial correlation analyses between the GOME and ISCCP data sets (annual average) of effective cloud fraction (red) and cloud amount (blue). After the ISCCP cloud amount is corrected for the effect of changing optical depth, improved agreement with the GOME data is found. The left panel shows the results for all data between $65^{\circ} \mathrm{N}$ and $65^{\circ} \mathrm{S}$ latitude including also snow and ice covered observations. The right panel shows the results between $40^{\circ} \mathrm{N}$ and $40^{\circ} \mathrm{S}$.

positive (negative) anomaly of ST is associated with a negative (positive) anomaly in $\mathrm{CF}$ or $\mathrm{O}_{2}$ absorption. One prominent exception is the pronounced positive correlation of the $\mathrm{CF}$ versus ST over the tropical oceans close to the equator.

From the correlation analyses we determined the slopes of the regression of the monthly $\mathrm{CF}$ anomalies versus those of the ST (Fig. 10, top). The changes in CF with increasing ST are negative for most parts of the globe, except over the tropical oceans close to the equator. These findings are in good agreement with those of Bony et al. (1997a), who found a negative correlation of CF (and cloud optical depth) for $\mathrm{ST}<26^{\circ} \mathrm{C}$ and a positive correlation for $\mathrm{ST}>26^{\circ} \mathrm{C}$.

We also determined the slopes of the regression for the $\mathrm{O}_{2}$ absorption anomalies versus those of the ST. From these correlations and those of the CF versus ST (Fig. 10, top), we calculated the changes in the CTH per degree ST (Fig. 10, bottom) using our radiative transfer model results (Sect. 2.4). Over almost the whole globe, positive temperature anomalies are correlated with increases of CTH. Very strong changes in CTH are found over the tropical oceans close to the equator. Again our findings are in good agreement with those of Bony et al. (1997a), who found a weak positive correlation of CTH for $\mathrm{ST}<26^{\circ} \mathrm{C}$ and strong positive correlation for $\mathrm{ST}>26^{\circ} \mathrm{C}$. They find a strong increase of cloud top height (from about $500 \mathrm{mb}$ to $200 \mathrm{mb}$ ) for a temperature increase from about $26^{\circ}$ to $29^{\circ}$. Also Larson and Hartmann (2003) found an increasing CTH of tropical clouds for increasing ST. They found in particular that over tropical oceans, the frequency of situations with large scale uprising air and high clouds increases strongly for surface temperatures $>26^{\circ} \mathrm{C}$.

\subsection{Results for time series without the strong ENSO 1997/98}

It is interesting to compare the results of the correlation analyses for periods including or excluding the strong ENSO event 1997/98. In Fig. 11 the variations of CF and CTH with changing ST are shown, based on correlation studies excluding the period August 1997-July 1998. Comparing these results with those shown in Fig. 10, we find that over most parts of the globe the results are almost identical. Only over parts of the tropical oceans substantial differences are found. These findings indicate that results of our correlation studies are representative also for the natural temperature variations beyond strong ENSO events.

\subsection{Discussion of various error sources}

As stated in Sects. 2.2 and 2.3, the errors of the data products ( $\mathrm{CF}$ and $\mathrm{O}_{2}$ absorption) are typically by far smaller than the observed dependencies per degree ST change. For the CF the accuracy ranges from $2 \%$ to $5 \%$, for the $\mathrm{O}_{2}$ absorption the precision is $\sim 0.3 \%$ (here systematic effects cancel out during the normalisation). Nevertheless, there are a number of additional error sources (especially important for the correlation analyses), which are discussed in detail in this section.

One important question is whether the observed variation of the $\mathrm{O}_{2}$ absorption might be simply caused by the changes of atmospheric pressure and temperature associated with variations of ST. In particular at mid latitudes cloud free situations are e.g. typically accompanied by high pressure 

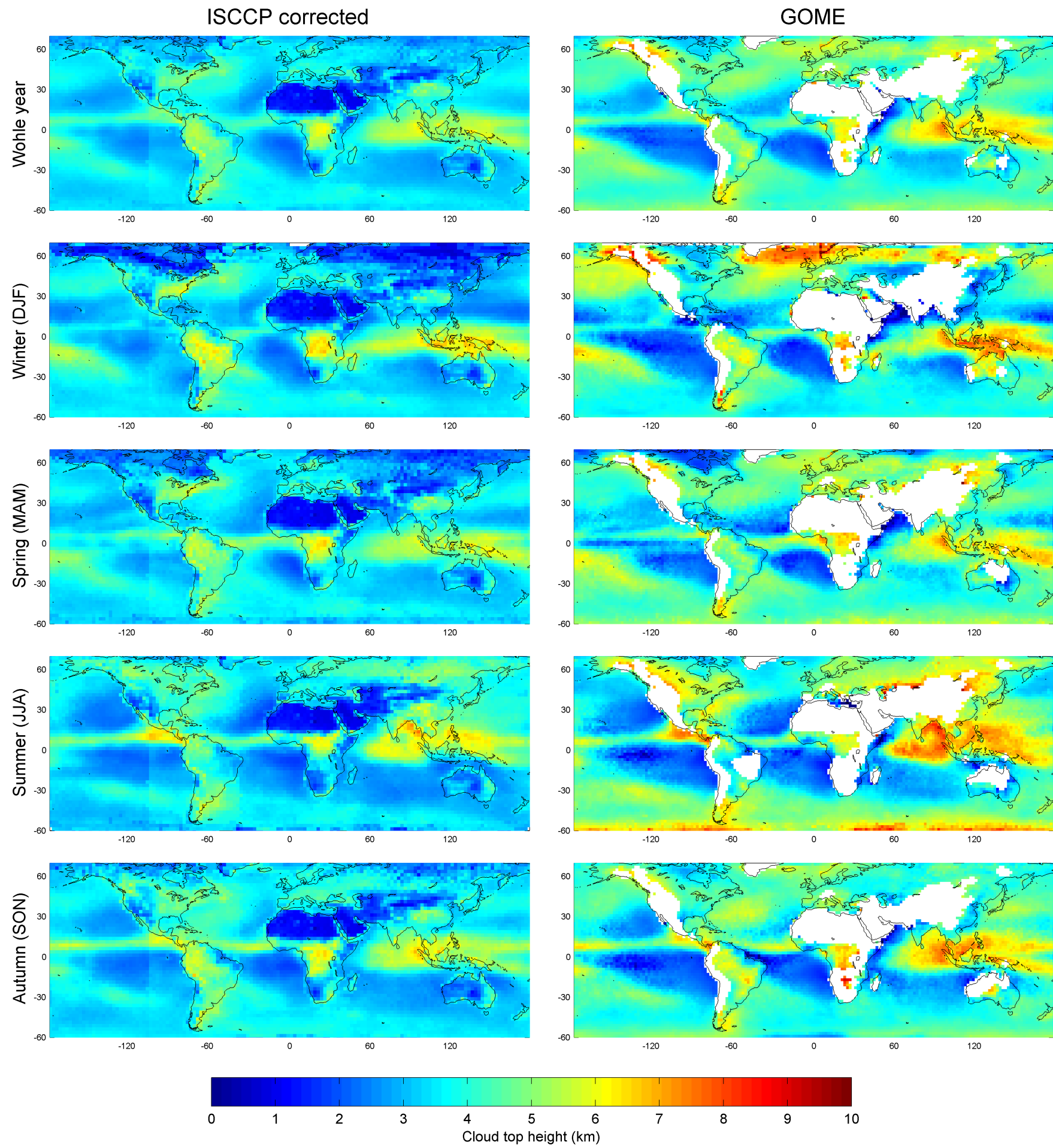

Fig. 6. Comparison of the effective cloud top height from GOME and ISCCP (annual and seasonal averages) for the period 1996-2003. For the ISCCP data a correction procedure was developed which converts cloud pressure and cloud optical depth into effective cloud height (see also text). Note that in polar regions the GOME data are partly affected by snow and ice. For areas with low effective cloud fraction and high surface elevation, no meaningful inversion was possible with the current version of our algorithm (see text). 

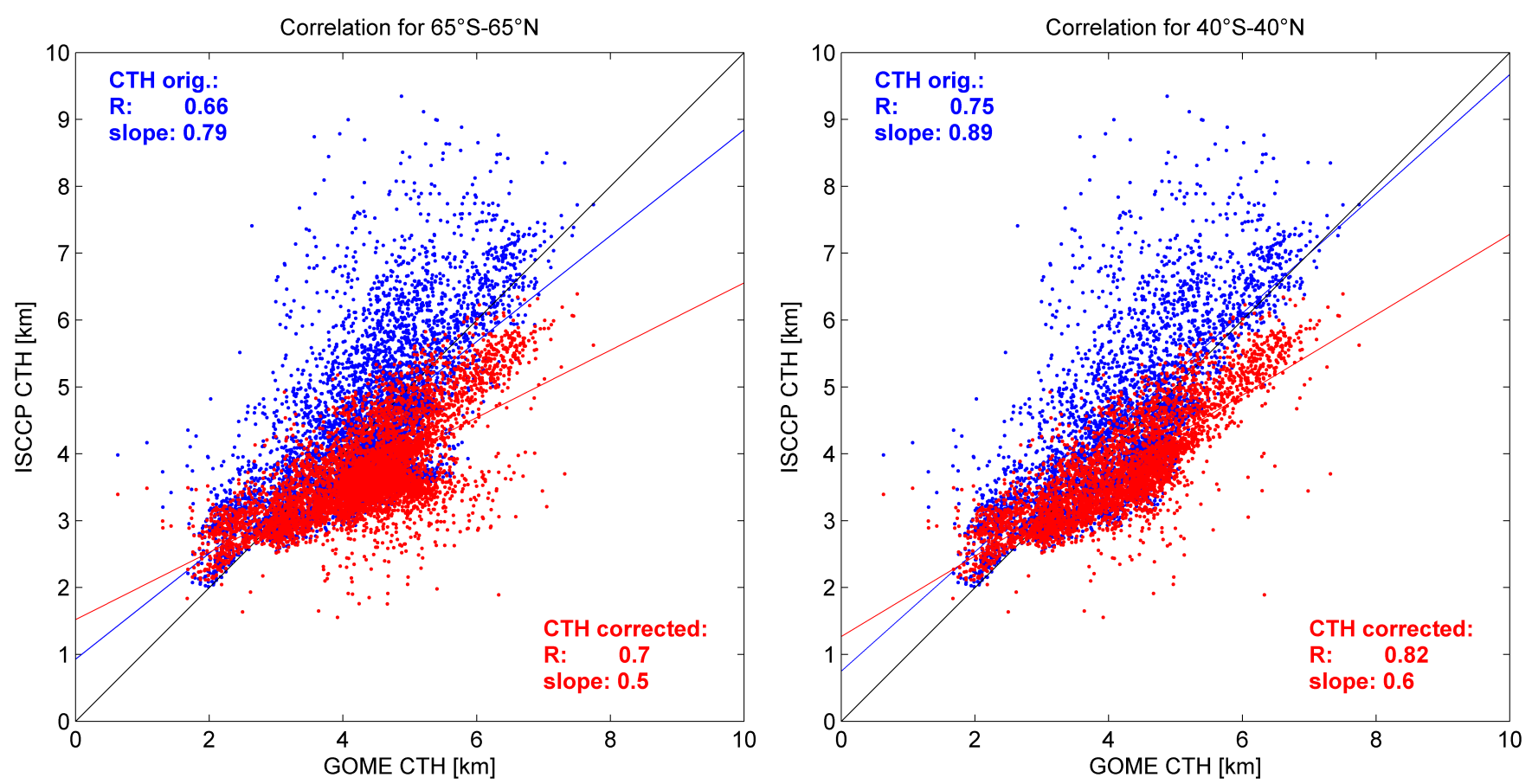

Fig. 7. Correlation analyses between the GOME and ISCCP data sets (spatial variation of the annual average) of cloud height (red: uncorrected ISCCP top height, blue corrected ISCCP effective cloud top height). After the ISCCP data is corrected for the effect of changing optical depth, improved agreement with the GOME data is found. The left figure shows the results for all data between $65^{\circ} \mathrm{N}$ and $65^{\circ} \mathrm{S}$ latitude including also snow and ice covered observations. The right figure shows the results between $40^{\circ} \mathrm{N}$ and $40^{\circ} \mathrm{S}$.

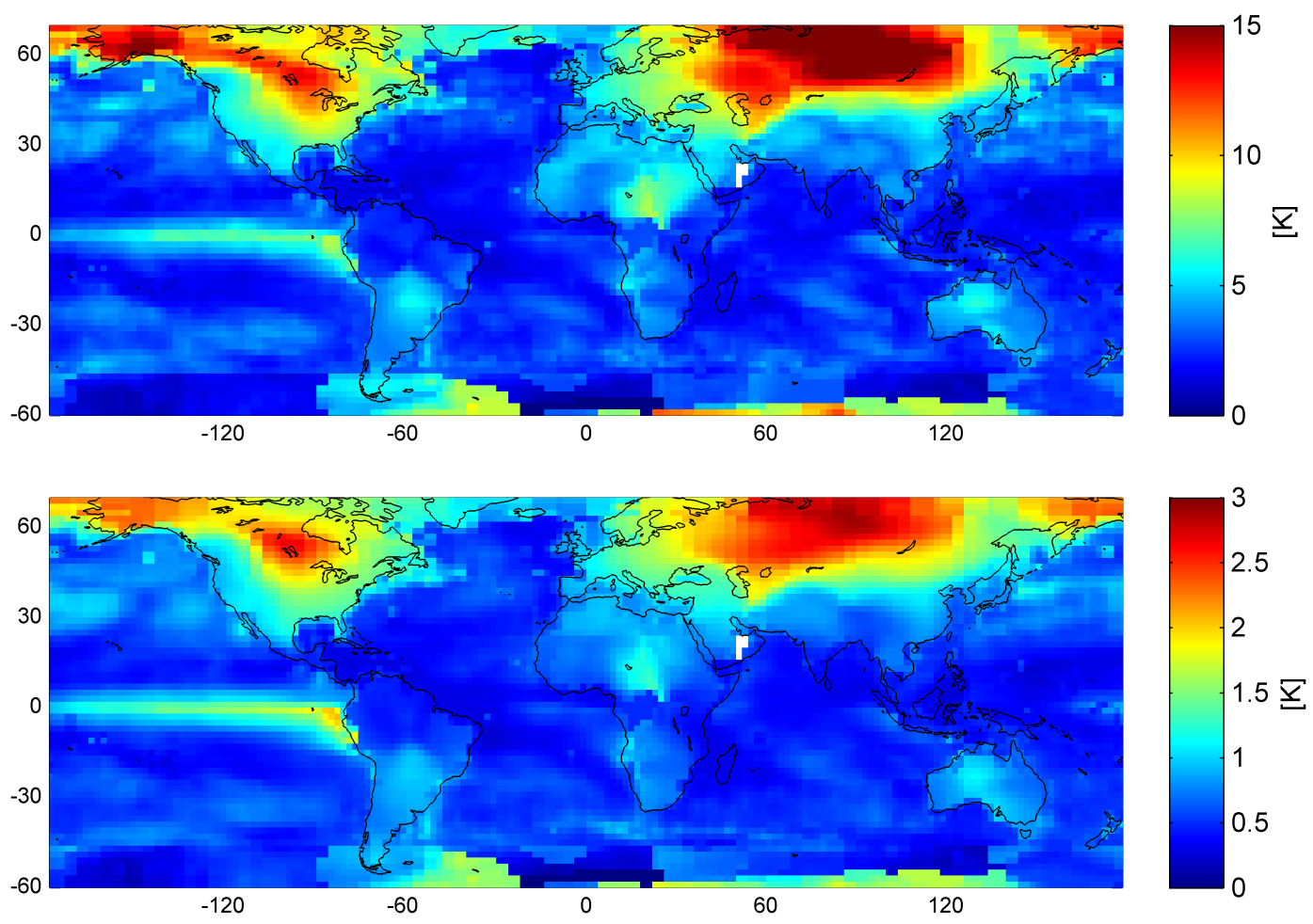

Fig. 8. Global distribution of the maximum amplitude (top) and standard deviation (bottom) of the monthly anomalies of the ST. The strongest variation is found over the continents. 

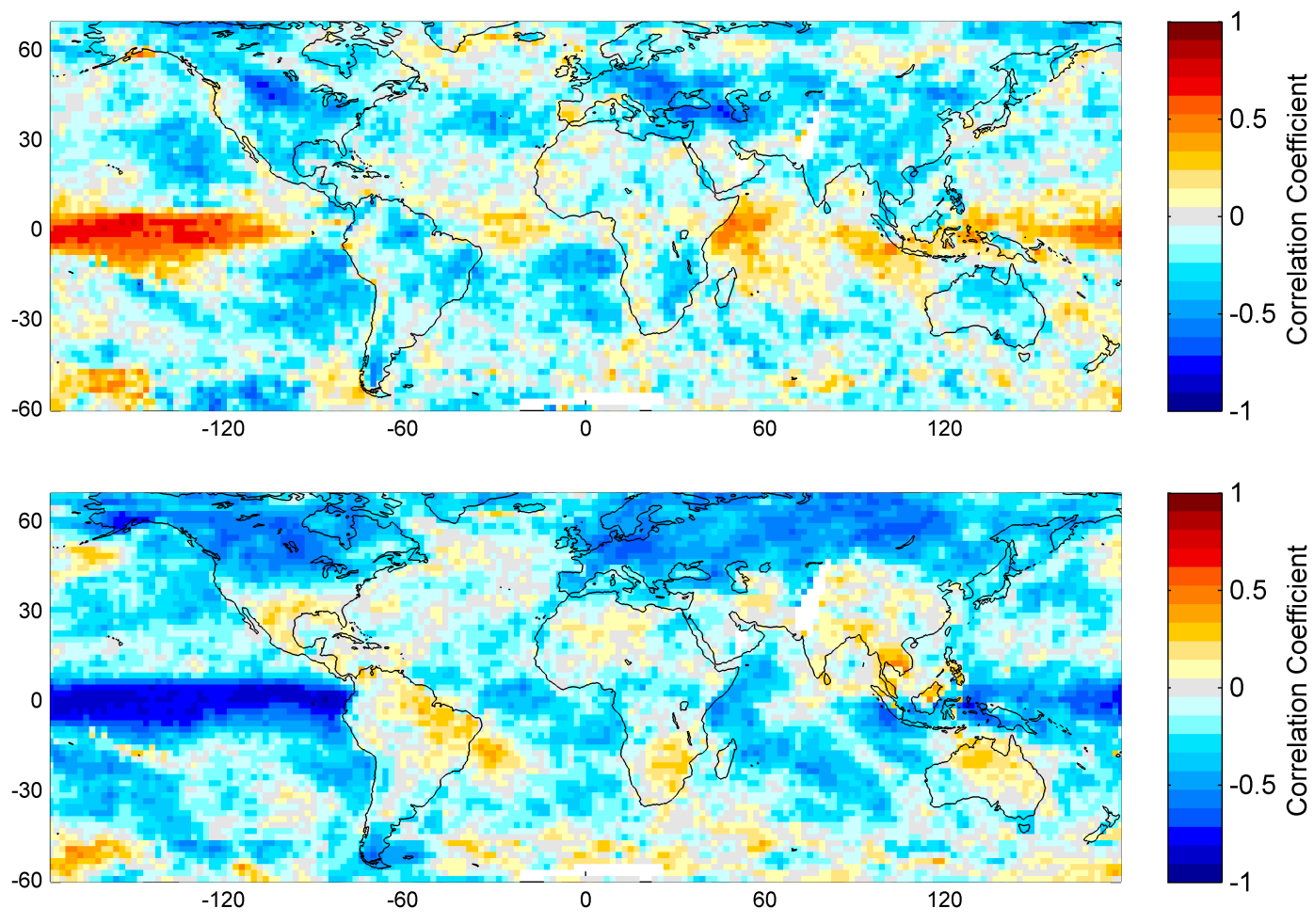

Fig. 9. Top: Correlation coefficients of the monthly anomalies of the effective cloud fraction versus surface-near temperature (top) and the $\mathrm{O}_{2}$ absorption versus surface-near temperature (bottom).

systems. However, from a quantitative analysis it turns out that the magnitude (and for most regions also the sign) of the observed $\mathrm{O}_{2}$ absorption changes can not be explained by the direct influence of these meteorological parameters.

It should be also noted that for large SZA ( $>$ about $80^{\circ}$, corresponding to latitudes poleward of about $60^{\circ}$ ), several effects can lead to increasing uncertainties compared to observations at lower SZA. First, because of the long atmospheric light paths, the relative contribution of Rayleigh scattering to the total observed radiance increases. Since one inversion scheme is applied to the whole range of SZA, this leads to systematic errors up to $5 \%$ for $\mathrm{SZA}<70^{\circ}$ and up to $20 \%$ for SZA of $85^{\circ}$. Second, because of the increased $\mathrm{O}_{2}$ absorption, the non-linearity between the measured $\mathrm{O}_{2}$ absorption and the integrated $\mathrm{O}_{2}$ concentration along the atmospheric absorption path increases (see above). Third, and probably most important, the probability of interference with snow and ice-covered surfaces increases. The first two effects might lead to an error in the magnitude (but not the sign) of the calculated CTH change. The third effect, however, might even affect the sign of the calculated change in CTH (and also CF) per degree ST for some regions of the world. From correlation analyses for individual seasons (not shown) we found that snow and ice interference is typically not the dominant effect at high latitudes. Nevertheless, for detailed interpretation of our results (e.g. comparison to models), high latitude data should be excluded as long as no detailed information on the seasonal variation of snow and ice cover is included in the radiative transfer modeling. In this study we restricted the analyses to latitudes between $70^{\circ} \mathrm{N}$ and $60^{\circ} \mathrm{S}$. It might be interesting to note here, that in principle, satellite observations of the $\mathrm{O}_{2}$ absorption could yield very valuable information on cloud properties over snow and ice covered surfaces (for which observations in the thermal IR have limited sensitivity). However, this method is only useful in cases, for which the surface albedo is known from other sources. For example, over regions with permanent snow or ice cover, the observation of the $\mathrm{O}_{2}$ absorption could be a very interesting option.

In our radiative transfer calculations, simplified homogenous cloud layers were assumed. In the presence of complex cloud formations, the photon paths between separated cloud fragments can become important because they can enhance the $\mathrm{O}_{2}$ absorption. In the case of horizontally broken cloud fields, the additional horizontal photon paths typically increase the $\mathrm{O}_{2}$ absorption compared to a homogenous cloud layer with similar total optical depth. Taking this effect into account, the observed decrease of the $\mathrm{O}_{2}$ absorption with increasing ST might be partly also caused by a change in the horizontal homogeneity of the cloud cover (towards a horizontally more homogenous distribution). However, from sensitivity studies using our radiative transfer model, we find that the magnitude of the observed changes in the $\mathrm{O}_{2}$ absorption can hardly be explained by this effect. 

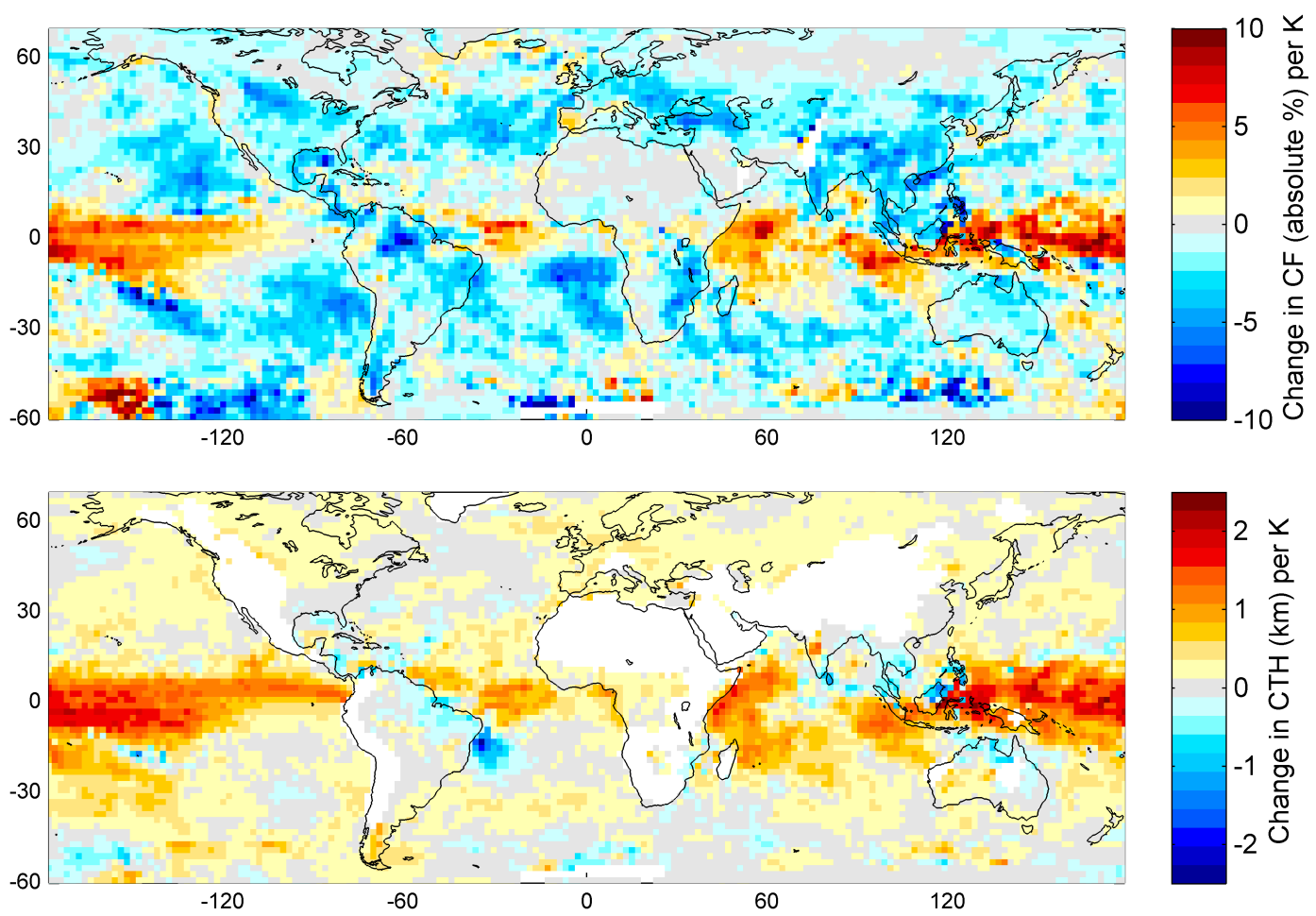

Fig. 10. Absolute changes of the effective cloud fraction (CF, top) and effective cloud top height (CTH, bottom) with increasing surface-near temperature (ST). The changes of the CF are expressed as \% (absolute CF) per degree ST; those of the CTH are expressed as km per degree ST. Note that for high latitudes (poleward of about $60^{\circ}$ ) our results have increased uncertainties because of the high solar zenith angles and possible interference with ice and snow covered surfaces (see supplementary information). For areas with low effective cloud fraction and high surface elevation, no CTH determination was possible with the current version of our algorithm (see text).

Also vertical inhomogeneities (cloud layers) can increase the $\mathrm{O}_{2}$ absorption due to enhanced photon paths between separate cloud layers. From radiative transfer calculations we found that this effect is especially pronounced if rather thin cloud layers (optical depth $<5$ ) are located above cloud layers with higher optical depth. For such cases, an increase of the altitude of the thin cloud layer can even increase the $\mathrm{O}_{2}$ absorption (the shielding effect is then slightly overcompensated by the increased path lengths of the photons "reflected" between the cloud layers). Thus, in principle, an observed decrease of the $\mathrm{O}_{2}$ absorption could even indicate a decrease of the height of a thin cloud layer above the thick cloud layer located below. However, again this effect is rather small: an upward shift of a thin cloud located above a thick cloud can cause an increase of the $\mathrm{O}_{2}$ absorption which is at maximum still three times smaller than the corresponding decrease of the $\mathrm{O}_{2}$ absorption caused by the same vertical shift of a thick cloud (this effect would become even smaller if an asymmetry parameter of 0.75 is used, which is more representative for ice clouds). Thus this effect can by far not explain the observed changes in the $\mathrm{O}_{2}$ absorption. We conclude that only a change in the height of cloud layers with high optical depth (optical depth $>$ about 10) can explain the observed large changes in the $\mathrm{O}_{2}$ absorptions due to the shielding ef- fect. Changes of the inhomogeneities in vertical and horizontal direction might explain only part of the observed $\mathrm{O}_{2}$ absorption changes.

The uncertainties of the GOME CTH are thus difficult to quantify, because they depend on many assumptions of the radiative transfer modeling, which can strongly differ from the real conditions. The CTH presented here represent the upper boundary of assumed horizontally homogenous clouds with a vertical extension of $1 \mathrm{~km}$ and an optical depth of 50 . From the comparison with ISCCP CTH it was found that the GOME CTH describes well the general global distribution, but shows systematic differences depending on season and location.

In summary, we conclude that except in polar regions, the results of the correlation analyses can be interpreted in a quantitative way only for the $\mathrm{CF}$. For the $\mathrm{CTH}$, the results of the correlation analyses can be only considered as qualitative information. Note also that a more meaningful interpretation of the GOME observations is possible if a GOME simulator is applied to model data (see Sect. 3.3). 

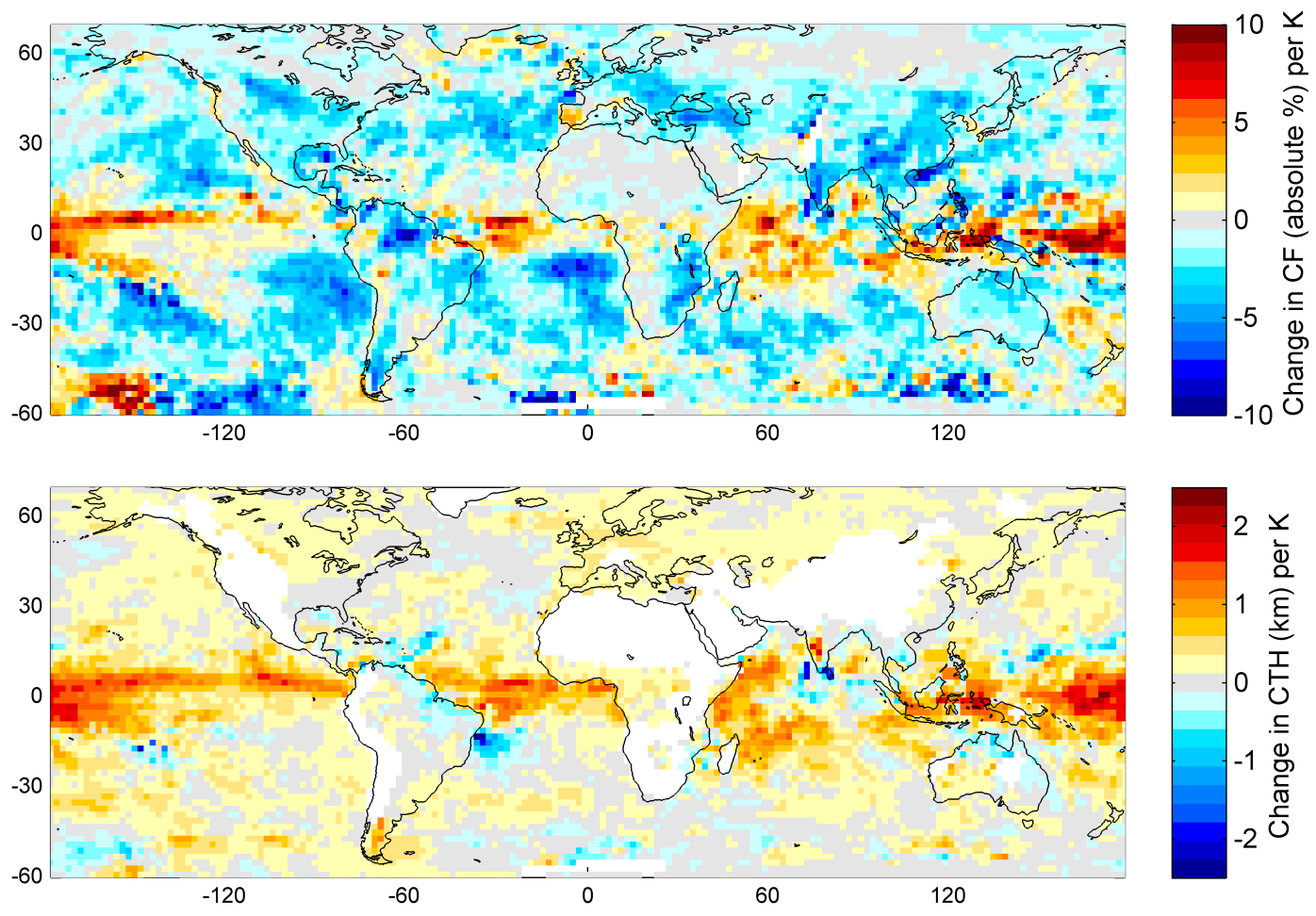

Fig. 11. Same as Fig. 10, but excluding the strong ENSO event (August 1997-July 1998). Even over the tropical oceans the differences compared to Fig. 8 are rather small. For areas with low effective cloud fraction and high surface elevation, no CTH determination was possible with the current version of our algorithm (see text).

\subsection{A GOME simulator for effective cloud fraction and $\mathrm{O}_{2}$ absorption}

An advanced way to compare the GOME observations to the results of atmospheric models would be to directly simulate the observed quantities, namely the $\mathrm{O}_{2}$ absorption at $630 \mathrm{~nm}$ and the $\mathrm{CF}$, from the output of atmospheric models. In such a way especially the effects of vertical cloud structures (e.g. multiple cloud layers) could be directly taken into account and ambiguities could be avoided. Thus, the comparison of model results and measurements would be more straight forward. In the following the basic requirements for such a GOME simulator are discussed.

The basic step of the simulator would be to convert the model output (e.g. microphysical properties, or liquid water content) into vertical profiles of optical properties (e.g. extinction coefficient, asymmetry parameter and single scattering albedo). In the next step, the $\mathrm{O}_{2}$ absorption and the observed radiance are calculated based on these input parameters (and also depending on the viewing geometry and temperature and pressure profiles). In the last step the modelled results are mapped to the area of the satellite observation. Depending on the spatial resolution of the model and satellite observation, this step might include the averaging of different model grid cells. Also a decision has to be made whether single satellite observations or temporal averages should be compared to the model results.
In principle for all these steps, procedures are already available (including e.g. our radiative transfer model) and can be implemented in the near future. It should also be noted that in more elaborate versions of a GOME simulator, also full 3-dimensional cloud structures (including horizontal gradients) might be considered. Similar GOME simulators could also address other cloud sensitive parameters like e.g. the Ring effect or the absorptions of the oxygen molecule or dimer at other wavelengths.

\section{Conclusions}

We applied a new method to investigate the relationships of $\mathrm{CF}$ and CTH with surface-near temperature based on the correlation of monthly anomalies. This method allows to extract information on these relationships from rather short periods of time. We found a negative correlation of effective cloud fraction (CF) with surface near temperatures (ST) for almost the whole globe, except the tropical oceans. For the effective cloud top height $(\mathrm{CTH})$ a positive relation to ST variations was found for almost the whole globe, with the highest changes in the tropics. The observed relationships are new and in itself interesting experimental results, but might also provide information on cloud climate feedback. Since cloud climate feedback involves complex interactions, depending especially on cloud type, location and season, the 
interpretation of our results with respect to climate feedback is not straightforward. Therefore, one conclusion of our study is that the results should aim to serve as a test case for climate models. For that purpose, recommendations for the construction of a GOME simulator are given (Sect. 3.3). A GOME simulator would allow a detailed comparison of the model results to GOME observations and could especially yield information on the vertical cloud structure. From our detailed comparison of cloud properties from GOME and ISCCP we found overall good agreement. It also turned out that GOME observations can yield independent and complementary information on cloud properties (especially on the vertical structure), which might be worth to be considered in climate research.

In addition to model comparisons, it can be instructive to relate our results to the general dependencies of cloud forcing, especially with respect to cloud cover and cloud top height. These dependencies can be summarised as follows:

a) in general, clouds tend to cool the Earth-atmospheresystem. However, this depends especially on season and latitude. The cooling effect of clouds is especially strong in the summer hemisphere (Stephens, 2005; Ramanathan et al., 1989; Harrison et al., 1990).

b) the cloud greenhouse effect increases with increasing cloud top height (Stephens, 2005; Cess et al., 1992; Kubar and Hartmann, 2007).

Based on the first dependency, no clear general conclusions can be drawn here. The only significant conclusion might be that the negative correlation between ST and CF indicates a positive cloud feedback (especially in the summer hemisphere). From the second dependency, however, we conclude that over almost the whole globe, our results indicate a positive cloud feedback. Note that these dependencies might only serve as an indication for the cloud feedback, since they describe local correlations of cloud properties and surface temperatures. Cloud climate feedback will, however, depend also on large scale changes which might not be well reflected by our results. Nevertheless, our new approach of correlating monthly anomalies might also have some advantages. It describes cloud-temperature relationships for the "natural" variability at fixed locations over 7.5 years, while other studies investigate changes associated with e.g. volcanic eruptions or ENSO events, or investigating the spatial variability. Here it is interesting to note that the observed correlations are largely independent on whether the strong ENSO event 1997/98 is included in the analysis or not. Similar relationships between the $\mathrm{CF}, \mathrm{O}_{2}$ absorption and ST as derived in this study are found in the spatial distribution of trends (Wagner et al., 2006b) for the period January 1996-December 2002.

Acknowledgements. We like to thank the European Space Agency (ESA) operation center in Frascati (Italy) and the "Deutsches Zentrum für Luft- und Raumfahrt" (DLR, Germany) for making the ERS-2 satellite spectral data available. Surface-near temperature data are from the Goddard Institute for Space Studies (GISS) (Hansen et al., 2001; Reynolds et al., 2002), http://www.giss.nasa.gov/data/update/gistemp/). ISCCP data are taken from the International Satellite Cloud Climatology Project (ISCCP, see e.g. Schiffer and Rossow, 1983; Rossow and Schiffer, 1999, and http://isccp.giss.nasa.gov/climanal.html).

Edited by: J. Quaas

\section{References}

Bergman, J. W. and Salby, M. L.: Diurnal variations of cloud cover and their relationship to climatological conditions, J. Climate, 9, 2802-2820, 1996.

Bony, S., Lau, K.-M., and Sud, Y. C.: Sea surface temperature and large-scale circulation influences on tropical greenhouse effect and cloud radiative forcing, J. Climate, 2055-2077, 1997a.

Bony, S., Sud, Y., Lau, K.-M., Susskind, J., and Saha, S.: Comparison and assessment of NASA/DAO and NCEP-NCAR reanalyses over tropical oceans: atmospheric hydrology and radiation, J. Climate, 1441-1462, 1997b.

Bony, S. and Dufresne, J.-L.: Marine boundary layer clouds at the heart of tropical cloud feedback uncertainties in climate models, Geophys. Res. Lett., 32, L20806, doi:10.1029/2005GL023851, 2005.

Burrows, J. P., Weber, M., Buchwitz, M., Rozanov, V., LadstätterWeißenmayer, A., Richter, A., DeBeek, R., Hoogen, R., Bramstedt, K., Eichmann, K.-U., Eisinger, M., and Perner, D.: The Global Ozone Monitoring Experiment (GOME): Mission Concept and First Scientific Results, J. Atmos. Sci., 56, 151-175, 1999.

Cess, R. D., Potter, G. L., Blanchet, J. P., et al.: Intercomparison and interpretation of cloud-climate feedback processes in nineteen atmospheric general circulation models, J. Geophys. Res., 95, 16601-16615, 1990.

Cess, R. D., Harrison, E. F., Minnis, P., Barkstrom, B. R., Ramanathan, V., and Kwon, T. Y.: Interpretation of seasonal cloudclimate interactions using Earth Radiation Budget Experiment data, J. Geophys. Res., 97, 7613-7617, 1992.

Cess, R. D., Zhang, M. H., Ingram, W. J., Potter, G. L., Alekseev, V., Barker, H. W., Cohen-Solal, E., Colman, R. A., Dazlich, D. A., Del Genio, A. D., Dix, M. R., Dymnikov, V., Esch, M., Fowler, L. D., Fraser, J. R., Galin, V., Gates, W. L., Hack, J. J., Kiehl, J. T., Treut, H. L., Lo, K. K. W., McAvaney, B. J., Meleshko, V. P., Morcrette, J. J., Randall, D. A., Roeckner, E., Royer, J. F., Schlesinger, M. E., Sporyshev, P. V., Timbal, B., Volodin, E. M., Taylor, K. E., Wang, W., and Wetherald, R. T.: Cloud feedback in atmospheric general circulation models: An update, J. Geophys. Res., 101, 12 791-12 794, 1996.

Cess, R. D. and Udelhofen, P. M.: Climate change during 1985-1999: Cloud interactions determined from satellite measurements, Geophys. Res. Lett., 30, 1019, doi:10.1029/2002GL016128, 2003.

Deutschmann, T. and Wagner, T.: TRACY-II Users manual, University of Heidelberg (http://satellite.iup.uni-heidelberg.de/ $\sim$ tdeutsch/tracy-II/), 2006.

Fu, Q., Baker, M., and Hartmann, D. L.: Tropical cirrus and water vapor: an effective infrared iris feedback?, Atmos. Chem. Phys., 
2, 31-37, 2002,

http://www.atmos-chem-phys.net/2/31/2002/.

Grzegorski, M., Wenig, M., Platt, U., Stammes, P., Fournier, N., and Wagner, T.: The Heidelberg iterative cloud retrieval utilities (HICRU) and its application to GOME data, Atmos. Chem. Phys., 6, 4461-4476, 2006,

http://www.atmos-chem-phys.net/6/4461/2006/.

Hansen, J., Ruedy, R., Sato, M., Imhoff, M., Lawrence, W., Easterling, D., Peterson, T., and Karl, T.: A closer look at United States and global surface temperature change, J. Geophys. Res., 106, 23 947-23 963, 2001.

Hartmann, D. L., Moy, L. A., and Fu, Q.: Tropical convection and the energy balance at the top of the atmosphere, J. Climate, 14, 4495-4511, 2001.

Harrison, E. F., Minnis, P., Barkstrom, B. R., Ramanathan, V., Cess, R., and Gibson, G.: Seasonal variations of cloud radiative forcing derived from the Earth's Radiation Budget Experiment, J. Geophys. Res., 95, 18687-18 703, 1990.

Koelemeijer, R. B. A., Stammes, P., Hovenier, J. W., and de Haan, J. F.: Global distribution of effective cloud fraction and cloud top pressure derived from oxygen A band spectra measured bythe Global Ozone Monitoring Experiment: Comparison to ISCCP data, J. Geophys. Res., 107(D12), 4151, doi:10.1029/2001JD000840, 2002.

Koelemeijer, R. B. A., de Haan, J. F., and Stammes, P.: A database of spectral surface reflectivity in the range 335-772 $\mathrm{nm}$ derived from 5.5 years of GOME observations, J. Geophys. Res., 108(D2), 4070, doi:10.1029/2002JD002429, 2003.

Kubar, T. L., Hartmann, D. L., and Wood, R.: Radiative and convective driving of tropical high clouds, J. Climate, 20, 5510-5526, doi:10.1175/2007JCLI1628.1, 2007.

Larson, K. and Hartmann, D. L.: Interactions among cloud, water vapor, radiation, and large-scale circulation in the tropical climate, part I: sensitivity to uniform sea surface temperature changes, J. Climate, 16, 1425-1440, 2003.

Platt, U.: Differential optical absorption spectroscopy (DOAS), Air monitoring by spectroscopic techniques, edited by: Sigrist, M. W., Chemical Analysis Series, 127, John Wiley \& Sons, Inc., 1994.

Ramanathan, V., Cess, R. D., Harrison, E. F., Minnis, P., Barkstrom, B. R., Ahmad, E., and Hartmann, D.: Cloud radiative forcing and climate; Results from the Earth Radiation Budget Experiment, Science, 243, 57-63, 1989.

Ramanathan, V. and Inamdar, A.: The radiative forcing due to clouds and water vapor, Frontiers of Climate Modeling, edited by: Kiehl, J. T. and Ramanthan, V., Cambridge University Press, 119-151, 2006.

Reynolds, R. W., Rayner, N. A., Smith, T. M., Stokes, D. C., and Wang, W.: An improved in situ and satellite SST analysis for climate, J. Climate, 15, 1609-1625, 2002.

Rossow, W. B. and Schiffer, R. A.: Advances in understanding clouds from ISCCP, B. Am. Meteor. Soc., 80, 2261-2287, 1999.

Schiffer, R. A. and Rossow, W. B.: ISCCP: The first project of the World Climate Research Program, B. Am. Meteor. Soc., 64, 770784, 1983.

Soden, B. and Held, I.: An assessment of climate feedbacks in coupled ocean-atmosphere models, J. Climate, 19(14), 3354-3360, 2006.

Solomon, S., Qin, D., Manning, M., et al.: Climate Change 2007:
The Physical Science Basis, Contribution of Working Group I to the Fourth Assessment Report of the Intergovernmental Panel on Climate Change (IPCC), Cambridge University Press, Cambridge, United Kingdom and New York, NY, USA, 2007.

Stephens, G. and Greenwald, T. J.: The Earth's radiation budget and its relation to atmospheric hydrology 2. Observations of cloud effects, J. Geophys. Res., 96, 15 325-15340, 1991.

Stephens, G. L.: Cloud feedbacks in the climate system: A critical review, J. Climate, 18, 237-273, 2005.

Tian, B. and Ramanathan, V.: Role of clouds in surface and atmospheric energy budget, J. Climate, 15, 296-305, 2002.

United States Committee on Extension to the Standard Atmosphere: "U.S. Standard Atmosphere, 1976", National Oceanic and Atmospheric Administration, National Aeronautics and Space Administration, United States Air Force, Washington D.C., 1976.

Wagner, T., Heland, J., Zöger, M., and Platt, U.: A fast $\mathrm{H}_{2} \mathrm{O}$ total column density product from GOME - validation with in-situ aircraft measurements, Atmos. Chem. Phys., 3, 651-663, 2003, http://www.atmos-chem-phys.net/3/651/2003/.

Wagner, T., Beirle, S., Grzegorski, M., Sanghavi, S., and Platt, U.: El-Niño induced anomalies in global data sets of water vapour and cloud cover derived from GOME on ERS-2, J. Geophys. Res., 110, D15104, doi:10.1029/2005JD005972, 2005.

Wagner, T., Beirle, S., Grzegorski, M., and Platt, U.: Global trends (1996 to 2003) of total column precipitable water observed by GOME on ERS-2 and their relation to surface-near temperature, J. Geophys. Res., 111, D12102, doi:10.1029/2005JD006523, 2006a.

Wagner, T., Beirle, S., Grzegorski, M., and Platt, U.: Investigating the Earth's hydrological cycle using $\mathrm{H}_{2} \mathrm{O}$ VCDs and cloud related parameters from GOME-II, Proceedings of the 1st EPS/MetOp RAO Workshop ESRIN, Frascati, Italy, 1517 May 2006 (http://earth.esrin.esa.it/workshops/EPS_MetOp_ RAO_2006/proceedings/papers/p_wagne.pdf), 2006b.

Wagner, T., Burrows, J. P., Deutschmann, T., Dix, B., von Friedeburg, C., Frieß, U., Hendrick, F., Heue, K.-P., Irie, H., Iwabuchi, H., Kanaya, Y., Keller, J., McLinden, C. A., Oetjen, H., Palazzi, E., Petritoli, A., Platt, U., Postylyakov, O., Pukite, J., Richter, A., van Roozendael, M., Rozanov, A., Rozanov, V., Sinreich, R., Sanghavi, S., and Wittrock, F.: Comparison of Box-AirMass-Factors and Radiances for Multiple-Axis Differential Optical Absorption Spectroscopy (MAX-DOAS) Geometries calculated from different UV/visible Radiative Transfer Models, Atmos. Chem. Phys., 7, 1809-1833, 2007, http://www.atmos-chem-phys.net/7/1809/2007/.

Webb, M. J., Senior, C. A., Sexton, D. M. H., Ingram, W. J., Williams, K. D., Ringer, M. A., McAvaney, B. J., Colman, R., Soden, B. J., Gudgel, R., Knutson, T., Emori, S., Ogura, T., Tsushima, Y., Andronova, N., Li, B., Musat, I., Bony, S., and Taylor, K. E.: On the contribution of local feedback mechanisms to the range of climate sensitivity in two GCM ensembles, Clim. Dynam., 27(1), 17-38, 2006.

Williams, K. D., Ringer, M. A., Senior, C. A., Webb, M. J., McAvaney, B. J., Andronova, N., Bony, S., Dufresne, J.-L., Emori, S., Gudgel, R., Knutson, T., Li, B., Lo, K., Musat, I., Wegner, J., Slingo, A., and Mitchell, J. F. B.: Evaluation of a component of the cloud response to climate change in an intercomparison of climate models, Clim. Dynam., 26, 145-165, doi:10.1007/s00382-005-0067-7, 2006. 